\title{
Incidence, Pattern and Outcome of Birth Injuries as Seen in a Tertiary Hospital in Southern Nigeria
}

\author{
Boma Awoala West ${ }^{1}$, Tamunoiyowuna Okari \\ ${ }^{1,2}$ Department of Paediatrics, Rivers State University Teaching Hospital, Nigeria \\ Corresponding Author: Boma Awoala West
}

\begin{abstract}
Introduction: Birth injuries although inevitable should be avoided to prevent unnecessary neonatal morbidities and mortalities as well as hospital litigations.

Aim: To determine the incidence rate, pattern and outcome of birth injuries occurring in the Rivers State University Teaching Hospital.

Materials and Methods: An observational prospective study was carried out in the Special Care baby Unit of the hospital. A pre tested proforma was used to collect demographic and pregnancy information from mothers and demographic data, delivery history, type of birth injury and clinical outcome from babies whose parents consented to the study.
\end{abstract}

Results: Thirty-nine of the 5,692 babies delivered during the study period had birth injuries, giving an incidence rate of 6.9 per 1000 live births. The common birth injuries were neurological $(26.2 \%)$, extracranial $(23.8 \%)$ and soft tissue injuries (21.4\%). Cephalopelvic disproportion (36\%), diabetes mellitus in pregnancy (32\%) and prolonged labour (20\%) were commonly found complications of pregnancy among mothers whose babies had birth injuries. Birth injuries were commoner among males, babies born by normal vaginal delivery and those with birth weights between 2.5-3.9Kg. Neurological injuries were significantly associated with normal vaginal delivery and birth weights of $\geq 4 \mathrm{~kg}$ while soft tissue injuries were significantly associated with Caesarean section, $\mathrm{P}$ value $<0.05$. Although majority of them were discharged, mortality rate was $7.7 \%$.

Conclusion: Although the incidence of birth injury in this study was low, the morbidity and mortality associated with it are avoidable. Improved antenatal and delivery services are therefore necessary to reduce the incidence of birth injuries.

Keywords: Birth injury; Incidence; Pattern; Outcome; Tertiary hospital; Nigeria

\section{INTRODUCTION}

Birth injuries are inevitable as long as babies are born. Birth injury is a structural destruction that occurs in the body of a neonate during labour and delivery. ${ }^{[1]}$ These injuries are usually as a result of tractional or compressional forces acting on the body of the baby during labour and delivery. ${ }^{[2]}$ There is paucity of data on birth injuries in Africa, and incidence rates are quite variable depending on the geographical region, the capability of the health facilities in that region, study design among other factors. The incidence rates in Africa ranges from 11-57 per 1000 live births. ${ }^{[3-6]}$ A study in Iraq $^{[7]}$ recorded an incidence rate of 22 per 1000 and 22.22 per 1000 live births in India. ${ }^{[8]}$

Birth injuries could be as a result of maternal, fetal and delivery factors. Maternal factors include age of the pregnant woman as those younger than 16 years or older than 35 years are prone to having babies with birth injuries. Other maternal factors are parity, short stature and women with contracted pelvis because of the likelihood of them having cephalopelvic disproportion. $^{[1,2]}$ The fetal factors include prematurity, fetal macrosomia, abnormal lie (breech and transverse) at term, abnormal presentations like face, brow or compound presentation during labour. Studies have 
shown that there is a higher risk of babies having birth injuries when delivered vaginally compared to a caesarean section delivery. ${ }^{[4-6]}$ Instrumental deliveries such as forceps and vacuum deliveries also pose a greater risk of babies having birth injuries. ${ }^{[2]}$

There are different forms of birth injuries. These injuries could be classified as intracranial or neurological, extracranial, soft tissue, musculoskeletal and injuries to intra-abdominal organs. ${ }^{[1,2,9]}$

It is desirable to avoid birth injuries as much as possible as its consequences could sometimes be dire and life threatening. Most times these injuries are minor, mild and self-limiting but sometimes serious and could significantly contribute to the burden of neonatal morbidities and mortality. In addition, it could result in prolonged hospital stay, increase the cost of neonatal care and result in long-term disabilities. ${ }^{[6,8,9]}$

It is therefore imperative for skilled health workers to attend to pregnant women in order to identify the risk factors that could predispose neonates to birth injuries early in the course of the pregnancy. With the rising awareness of caregivers on their patient rights and increasing litigation of health workers and health facilities and the fact that birth injuries is sometimes perceived as clinical negligence by parents, ${ }^{10]}$ it has become necessary to identify the peculiar factors associated with birth injuries in our facility in order to reduce its incidence and the resultant neonatal morbidity, mortality and litigations against the health facilities. Besides, findings from this study could also be incorporated into the hospital's delivery and neonatal care protocols in order to offer better health care services to pregnant mothers and newborns with birth injuries.

This study is therefore aimed at evaluating the incidence, pattern and outcome of birth injuries in Rivers State University Teaching Hospital (RSUTH), Port Harcourt, a tertiary health facility in the southern part of Nigeria.

\section{MATERIALS AND METHODS Study design}

This is a prospective observational study carried out on live born neonates in the Special Care Baby (SCBU) Unit of the Rivers State University Teaching Hospital (RSUTH) over 3 years, from $1^{\text {st }}$ February 2018 to $31^{\text {st }}$ January 2021.

\section{Study site}

Rivers state University Teaching Hospital is located in the metropolitan capital city of Rivers State, Port Harcourt, in the South-South region of Nigeria. It is a tertiary health facility owned by the Rivers State Government. It is a 375 bedded hospital with different clinical departments and sub specialities in addition to nonclinical departments. It is also a referral hospital that serves all the state owned primary and secondary health facilities, private hospitals and referrals from neighbouring States in Nigeria.

The SCBU, a unit under the department of Paediatrics is a 30 bed unit that admits all neonates aged 0-28 days, delivered in the hospital and those whose mothers registered and delivered in state owned primary health centres and General Hospitals in the state.

It operates every day and is manned by two consultant Paediatricians, senior and junior residents in Paediatrics, house officers, paediatric nurses of different cadres in addition to other auxiliary and administrative staff.

\section{Study population}

Study population was made up of all neonates born in RSUTH during the study period and all those admitted into the SCBU with birth injuries within this period were recruited.

\section{Inclusion and exclusion criteria}

The inclusion criteria were babies aged 0-28 days diagnosed with birth injuries by one of the trained researchers and whose parents gave written consent to be a part of the study. Babies aged 0-28 days with birth 
injuries whose parents refused to give written informed consent were excluded from the study.

\section{Methods}

The babies with birth injuries were consecutively recruited by trained researchers throughout the study period. A pre tested research proforma was used to obtain information from the babies and their mothers.

Before the commencement of the research, all members of the research team were trained by the lead researchers to identify and make a diagnosis of birth injury on admitted neonates following a full physical examination, request for relevant laboratory investigations, complete the research proforma and care for and follow up such neonates until they were either discharged from the SCBU, discharged against medical advice or died. The aim of the study and the research protocols were also explained to parents and written informed consent obtained from them. Information obtained from the mothers and their medical records were age, marital status, parity, educational level, occupation and complications of pregnancy.

Information obtained from the babies and recorded on the proforma were gestational age, gender, mode of delivery, type of presentation, birth weight and APGAR score. The type of birth injury was also recorded on the proforma in addition to the duration of hospital stay and clinical outcome of the baby whether discharged home, discharged against medical advice or died.

\section{Ethical clearance}

Ethical clearance for the study was obtained from the Ethics Committee of the hospital. Written informed consent was also obtained from the parents/caregivers of the babies.

\section{Statistical Analysis}

The information obtained were entered into an excel sheet and analysed with Statistical Package for Social Sciences (SPSS) version 23. The Pearson Chi square was used to test for association between categorical variables. Statistical significance was set at $\mathrm{P}$ value of 0.05 at $95 \%$ confidence interval.

\section{RESULT}

\section{Sociodemographic characteristics of neonates with birth injuries}

Table I: Sociodemographic characteristics of neonates with birth injuries

\begin{tabular}{|lc|}
\hline Variables (\%) & Frequency, $\mathbf{n}=39$ \\
Sex & $25(64.1)$ \\
Male & $14(35.9)$ \\
Female & \\
Gestational age (weeks) & $11(28.2)$ \\
$<37$ & $28(71.8)$ \\
$37-42$ & $0(0.0)$ \\
$\geq 42$ & \\
Mode of delivery & $20(51.3)$ \\
NVD & $19(48.7)$ \\
CS & \\
Type of presentation & $33(84.6)$ \\
Vertex & $4(10.3)$ \\
Breech & $2(5.1)$ \\
Face & \\
Birth weight (kg) & $5(12.8)$ \\
$<2.5$ & $19(48.7)$ \\
$2.5-3.9$ & $15(38.5)$ \\
$\geq 4.0$ & \\
Number of fetus & $38(97.4)$ \\
Singleton & $1(2.6)$ \\
Multiple & \\
Presence of perinatal asphyxia & $11(28.2)$ \\
Yes & $28(71.8)$ \\
No & \\
Duration of hospital stay (days) & $14(35.9)$ \\
$\leq 7$ & $25(64.1)$ \\
$>7$ & NVD-Normal vaginal delivery, CS-Caesarean section \\
\hline &
\end{tabular}

There were 5,692 live births during the period of study of which 39 were admitted into the SCBU for birth injuries giving an incidence rate of birth injuries among admitted neonates as 6.9 per 1000 live births. Males predominated 25(64.1\%) with a M:F ratio of $1.8: 1$. The mean gestational age of neonates with birth injuries was $37.9 \pm 2.7$ weeks. Neonates delivered between 37-42weeks gestation had most birth injuries 28(71.8\%). Majority of the babies were delivered via normal vaginal delivery (NVD) 20(51.3\%), had vertex presentation $33(84.6 \%)$ and birth weight of $2.5-3.9 \mathrm{~kg}, 19(48.7 \%)$. The mean birth weight of these neonates was $3.5 \pm$ $0.9 \mathrm{~kg}$. The babies were majorly singleton $38(97.4 \%)$, $11(28.2 \%)$ had perinatal 
Boma Awoala West et.al. Incidence, pattern and outcome of birth injuries as seen in a tertiary hospital in Southern Nigeria.

asphyxia and majority had duration of hospital stay of $>7$ days, $25(64.1 \%)$, Table I.

\section{Maternal sociodemographic characteristics}

Table II: Maternal sociodemographic characteristics

\begin{tabular}{|c|c|}
\hline $\begin{array}{l}\text { Variables } \\
\mathrm{n}=39(\%)\end{array}$ & Frequency, \\
\hline \multicolumn{2}{|l|}{ Mother's age (years) } \\
\hline $20-35$ & $34(87.2)$ \\
\hline$>35$ & $5(12.8)$ \\
\hline \multicolumn{2}{|l|}{ Marital status } \\
\hline Married & $38(97.4)$ \\
\hline Single & $1(2.6)$ \\
\hline \multicolumn{2}{|l|}{ Parity } \\
\hline $0-1$ & $22(56.4)$ \\
\hline$\geq 2$ & 17 (43.6) \\
\hline \multicolumn{2}{|l|}{ Mother's level of education } \\
\hline Primary & $2(5.1)$ \\
\hline Secondary & $18(46.2)$ \\
\hline Tertiary & 19 (48.7) \\
\hline \multicolumn{2}{|l|}{ Mother's occupation } \\
\hline Civil/public servant & $8(20.5)$ \\
\hline Business/Trader/Artisan & $26(66.7)$ \\
\hline Housewife & $5(12.8)$ \\
\hline
\end{tabular}

\section{Types of birth injuries}

Majority of mothers of neonates with birth injuries were 20-35years, $34(87.2 \%)$, had mean age of $30.5 \pm 4.8$ years and were mostly married, 38(97.4\%). Mothers with parity 0-1 predominated
$22(56.4 \%)$, had tertiary level of education $19(48.7 \%)$ and were mainly business women/traders and artisans 26(66.7\%), Table II.

There were 42 birth injuries with the commonest being neurological injuries $11(26.2 \%)$, extra-cranial injuries 10(23.8\%) and soft tissue injuries $9(21.4 \%)$ whereas the least common were eye injuries $6(14.3 \%)$ and skeletal injuries 6(14.3\%).

The neurological injuries observed were only Erb's palsy while the extracranial injuries were cephalheamatoma $7(70.0 \%)$, subgaleal haemorrhage $2(20.0 \%)$ and cervical heamatoma $1(10.0 \%)$. The soft tissue injuries observed were lacerations of the cheeks, thigh and scalp 6(66.7\%), skin erythema $2(22.2 \%)$ and oedema of the penile shaft $1(11.1 \%)$ whereas skeletal injuries observed were fracture of the femur $3(50.0 \%)$, fracture of the humerus $2(33.3 \%)$ and subluxation of the right elbow $1(16.7 \%)$. The eye injuries observed in the present study were only sub-conjunctival haemorrhages, figure 1 .

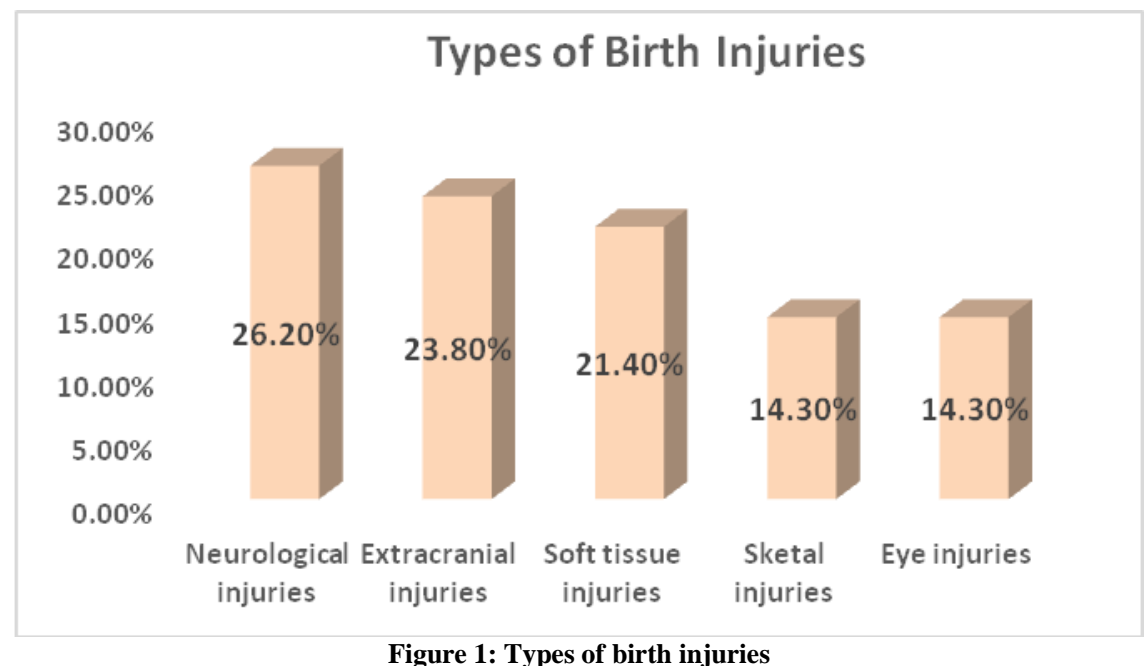

\section{Pregnancy complications of mothers of neonates with birth injuries}

The commonest

pregnancy

complications of mothers whose neonates had birth injuries were cephalopelvic disproportion (CPD) 9(36.0\%), diabetes mellitus in pregnancy $8(32.0 \%)$ and prolonged labour $5(20.0 \%)$ whereas the least were antepartum haemorrhage (APH) $1(4.0 \%)$ and abnormal lie 1(4.0\%), figure 2 . 
Boma Awoala West et.al. Incidence, pattern and outcome of birth injuries as seen in a tertiary hospital in Southern Nigeria.

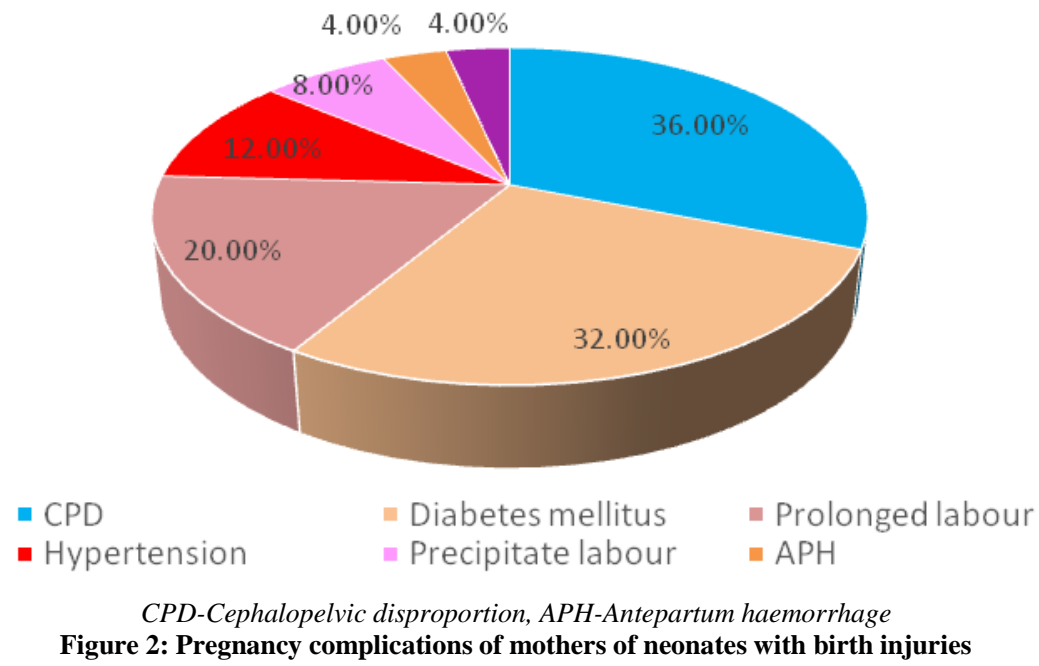

Association of birth injuries with mode of delivery, sex, birth weight and gestational age of neonates

Neurological injuries were significantly associated with mode of delivery $(\mathrm{P}$ value $=0.003)$ and birth weight
(P value $=0.010)$ of neonates whereas soft tissue injuries were significantly associated with mode of delivery $(\mathrm{P}$ value $=0.008)$ and sex $(P$ value $=0.047)$ of the babies. Birth injuries were not significantly associated with gestational age, Table III.

\begin{tabular}{|c|c|c|c|c|c|c|}
\hline \multirow[t]{2}{*}{ Birth injuries } & \multicolumn{3}{|c|}{$\begin{array}{l}\text { Mode of delivery } \\
\text { N (\%) }\end{array}$} & \multicolumn{3}{|c|}{$\begin{array}{l}\text { Sex, } \\
\mathbf{N}(\%)\end{array}$} \\
\hline & NVD & CS & $P$ value & Male & Female & P value \\
\hline Eye injuries & $4(20.0)$ & $2(10.5)$ & 0.661 & $4(16.0)$ & $2(14.3)$ & 1.000 \\
\hline Extracranial injuries & $5(25.0)$ & $5(26.3)$ & 1.000 & $8(32.0)$ & $2(14.3)$ & 0.279 \\
\hline Skeletal injuries & $2(10.0)$ & $4(21.1)$ & 0.407 & $4(16.0)$ & $2(14.3)$ & 1.000 \\
\hline Neurological injuries & $10(50.0)$ & $1(5.3)$ & $0.003^{*}$ & $9(36.0)$ & $2(14.3)$ & 0.266 \\
\hline \multirow[t]{3}{*}{ Soft tissue injuries } & $1(5.0)$ & $8(42.1)$ & $0.008^{*}$ & $3(12.0)$ & $6(42.9)$ & $0.047^{*}$ \\
\hline & \multicolumn{3}{|c|}{$\begin{array}{l}\text { Birth weight }[\mathrm{kg}] \\
\quad \mathrm{N}(\%)\end{array}$} & \multicolumn{3}{|c|}{$\begin{array}{c}\text { Gestational age [week] } \\
\text { N (\%) }\end{array}$} \\
\hline & $<4.0$ & $\geq 4.0$ & $P$ value & $<37$ & $\geq 37$ & P value \\
\hline Eye injuries & $3(12.5)$ & $3(20.0)$ & 0.658 & $0(0.0)$ & $6(18.8)$ & 0.568 \\
\hline Extracranial injuries & $9(37.5)$ & $1(6.7)$ & 0.057 & $2(28.6)$ & $8(25.0)$ & 1.000 \\
\hline Skeletal injuries & $4(16.7)$ & $2(13.3)$ & 1.000 & $2(28.6)$ & $4(12.5)$ & 0.290 \\
\hline Neurological injuries & $3(12.5)$ & $8(53.3)$ & $0.010^{*}$ & $1(14.3)$ & $10(31.3)$ & 0.649 \\
\hline Soft tissue injuries & $6(25.0)$ & $3(20.0)$ & 1.000 & $3(42.9)$ & $6(18.8)$ & 0.319 \\
\hline
\end{tabular}

Outcome of neonates with birth injuries

Of 39 neonates with birth injuries, $35(89.7 \%)$ were discharged home while $3(7.7 \%)$ died, Table IV.

Table IV: Outcome of neonates with birth injuries

\begin{tabular}{|lc|}
\hline Outcome & Frequency n $(\%)$ \\
\hline Discharged & $35(89.7)$ \\
Died & $3(7.7)$ \\
DAMA & $1(2.6)$ \\
Total & $39(100)$ \\
\hline
\end{tabular}

\section{DISCUSSION}

The incidence of birth injuries among neonates admitted in the neonatal unit of the Rivers State University Teaching
Hospital observed to be 6.9 per 1000 live births was comparable with the 5.7 per 1000 live births documented in Maiduguri, Borno state $^{[5]}$ in northern Nigeria. It was higher than the 3.26 per 1000 live births reported in India $^{[11]}$ and 0.8 per 1000 live births in Iran $^{[12]}$ but lower than the 11 per 1000 live births, 22 per 1000 live births, 22.22 per 1000 live births, 41.16 per 1000 live births, 23.7 per 1000 live births and 29 per 1000 live births in Enugu, ${ }^{[4]}$ southeast Nigeria, Iran, ${ }^{[7,13]}$ India, ${ }^{[8]}$ Finland $^{[14]}$ and the United States. ${ }^{[15]}$ This difference in the incidence rates could be attributed to the varying 
geographic locations, study designs, variations over time as well as the standard of obstetric practices. The very low incidence rate observed in $\operatorname{Iran}^{[12]}$ could also be attributable to the fact that it was a retrospective study unlike the present study which was done prospectively and as such the possibility of missing data. The varying incidence rates observed in Iran could also be attributed to variation over time as the two latter studies ${ }^{[7,13]}$ were done 10 years apart and thus the possibility of an improvement of their obstetric practice.

There was male preponderance in the present study which was in conformity with several studies in Nigeria ${ }^{[4,5,16-18]}$ and India. ${ }^{[11,19]}$ In contrast, Ray et al ${ }^{[20]}$ and Pinto et $\mathrm{al}^{[21]}$ reported female preponderance. This difference could not be easily explained although reports have shown that macrosomia which is a risk factor for birth injuries are commoner in males than females. ${ }^{[22]}$ In addition, Ricart et $\mathrm{al}^{[22]}$ in their studies also reported that maternal glucose tolerance status was a significant predictor of fetal macrosomia in the male gender.

Majority $(71.8 \%)$ of neonates with birth injuries in the present study were delivered at term with gestational ages of 37-42weeks. Similar observations were made by Pius et al, ${ }^{[5]}$ Abedzadeh-Kalahroudi et $\mathrm{al}^{[7]}$ and Osinaike et al. ${ }^{[16]}$ Kekki et a ${ }^{[14]}$ in their 21years retrospective study in Finland documented an increase in birth injury with gestational age; lowest in the extreme preterms and highest in late preterms and post term pregnancies.

More than half $(51.3 \%)$ of the neonates with birth injuries in the present study were delivered via normal vaginal delivery as was also observed in other parts of Nigeria, ${ }^{[4,5,16-18]}$ India, ${ }^{[11,19]}$ and Iran. ${ }^{[12]}$ Operative deliveries are usually declined by many women especially in the developing countries due to cultural and religious beliefs as well as its huge financial implications. Similarly, Mosavat and Zamani $^{[12]}$ observed that birth injuries were significantly more frequent in vaginal than
Caesarean section. Other studies have also shown reduction in the incidence of birth injuries with Caesarean section. ${ }^{[7,23]}$ It is noteworthy that instrumental delivery (vacuum/forceps) was not performed on any of the neonates with birth injuries in the present study and as such did not account for birth injuries. This was also the case in some parts of Nigeria ${ }^{[4,16]}$ and India. ${ }^{[11]}$ However, instrumental deliveries were responsible for $18 \%$ and $1.78 \%$ of birth injuries documented in other parts of Nigeria [5] and India ${ }^{[19]}$ respectively. Instrumental delivery has been known to be an important cause of birth injury especially when used by an inexperienced health personnel during labour and when done at the wrong time. ${ }^{[24]}$

Vertex or cephalic presentation accounted for greater than 3/4th $(84.6 \%)$ of cases of neonates with birth injuries in the present study. Similar observations were made by Osinaike et al, ${ }^{[16]}$ Onuoha et al ${ }^{[17]}$ and Rizwan-u-zama et $\mathrm{al}^{[19]}$ in Maiduguri (northern Nigeria), Lagos (south west) Nigeria and India respectively. However, Chukwubuike et al ${ }^{[4]}$ in Enugu, south east Nigeria reported about $2 / 3^{\text {rd }}$ of fetal presentation being vertex/cephalic.

Normal birth weights $(2.5-3.9 \mathrm{~kg})$ predominated whereas neonates with low birth weights $(<2.5 \mathrm{~kg})$ accounted for the least. The predominance of birth injuries in normal weight babies was also the case in other parts of Nigeria ${ }^{[5,16,18]}$ and India. ${ }^{[11,19]}$ Birth injuries least observed in low birth weight babies in the present study was however at variance with other studies ${ }^{[16,18]}$ where macrosomic babies (> 4.0kg) were observed to be the least common. This was surprising as macrosomic babies are usually at risk of birth injuries due to their large size as observed by Sauber-Schatz et al ${ }^{[15]}$ who documented higher birth weights $(>4.0 \mathrm{~kg}$ ) as being strongly associated with birth injuries.

There were more birth injuries among neonates of mothers with lower parity (0-1) as also documented by Chukwubuike et al ${ }^{[4]}$ and Prabhu et al ${ }^{[8]}$ in 
Enugu, south east Nigeria and India respectively. This corroborates the findings by Osinaike et al ${ }^{[16]}$ who showed that neonates of mothers with para $0-1$ were significantly more likely to have birth injuries. This was however contrary to reports by Onuoha et al ${ }^{[17]}$ and AbedzadehKalahroudi et al ${ }^{[7]}$ in Lagos, Nigeria and Iran respectively where neonates of mothers with higher parities $(>2)$ were reported to have more birth injuries. Inexperience or rigidity of the pelvis of nulliparous and Primiparous mothers could be responsible for the preponderance observed in the present study. This was also in consonance with the findings of Rizwan-u-zama et $\mathrm{al}^{[19]}$ which showed that $68 \%$ of neonates with birth injuries were of the $1^{\text {st }}$ birth order.

Cephalopelvic disproportion was the commonest pregnancy complication observed in mothers whose neonates had birth injuries followed by mothers with diabetes mellitus and mothers with prolonged labour. Cephalopelvic disproportion being the commonest pregnancy complication is not surprising as birth injuries are particularly prevalent when labour is prolonged and difficult as seen in CPD even in the presence of meticulous prenatal care. ${ }^{[7]}$ Infants of diabetic mothers are also at risk of injuries because of their large sizes. This was in consonance with observation made by Osinaike et al [16] which showed that infants of diabetic mothers were significantly more likely to have birth injuries. Interestingly, the present study showed that neurological birth injuries in neonates with larger weights $(\geq 4.0 \mathrm{~kg})$ were significantly more than those with smaller weights $(<4.0 \mathrm{~kg})$. This corroborates the findings by Njokanma et al ${ }^{[25]}$ that birth weights $>4.0 \mathrm{~kg}$ was associated significantly with a higher risk of birth injuries. Thus a high index of suspicion in pregnant women with risk factors with timely and appropriate intervention would prevent morbidity and mortality resulting from birth injuries. In addition, technologic advancements help in the prompt recognition of risk factors for birth injuries via the use of ultrasonography and fetal monitoring which help obstetrician take appropriate and timely decision on mode of delivery thereby reducing the incidence of birth injuries.

The commonest group of birth injuries observed in the neonatal unit of the Rivers State University Teaching Hospital was neurological injuries followed by extracranial and the soft tissue injuries while the least observed were the skeletal and eye injuries. Erb's palsy was the only neurological injury observed in the present study. Similarly, Erb's palsy was the commonest neurological injury observed in other parts of Nigeria, ${ }^{[4,5,18]}$ Finland $^{[14]}$ and $\operatorname{Iran}^{[7,13]}$ whereas facial nerve palsy was the commonest neurological injury observed in a study in India. ${ }^{[11]}$ Unlike in the present study where neurological injuries were the commonest birth injuries observed, cephalheamatomas which are extracranial injuries were documented as the commonest birth injuries in Enugu, ${ }^{[4]}$ south east Nigeria and Iran. ${ }^{[7,12,13]}$ Fractures were documented as the commonest injuries in India ${ }^{[11]}$ and in Finland $^{[14]}$ whereas caput succedenum was reported in Enugu, ${ }^{[18]}$ south east Nigeria, facial and skin injuries in Maiduguri, ${ }^{[5]}$ northern Nigeria, subconjunctival haemorrhage in Lagos, ${ }^{[16]}$ south west Nigeria and head \& neck injuries (abrasions, lacerations, ecchymosis) in India. ${ }^{[8]}$ It is pertinent to note that fracture of the femur was the commonest skeletal injury in the present study as similarly reported in some parts of Nigeria. ${ }^{[5,18]}$ In contrast, clavicular fracture which was not implicated in the present study was the commonest skeletal injuries in other studies carried out in other parts of Nigeria, ${ }^{[4]}$ India, ${ }^{[8,11]}$ Finland ${ }^{[14]}$ and Iran. ${ }^{[7,12,13]}$ These varying birth injuries could be attributed to the difference in geographic locations, varying criteria for the choice of delivery as well as variation over time. Interestingly, perinatal asphyxia which was not classified as a type of birth injury in the present study, was seen in a quarter of neonates who had birth injuries. The occurrence of perinatal asphyxia in neonates with birth injuries is not surprising as 
factors that predispose to perinatal asphyxia also could lead to birth injuries. Similar observation was also made by Osinaike et al ${ }^{[16]}$ and Ekwochi et al ${ }^{[18]}$ in Lagos and Enugu, Nigeria respectively.

In the present study, neurological injuries were significantly associated with the mode of delivery of the neonates and their birth weights while soft tissue injuries were significantly associated with mode of delivery and the sex of the neonates. This study showed that neurological injuries were commoner in neonates delivered via normal vaginal delivery and neonates whose birth weights were $\geq 4.0 \mathrm{~kg}$. This was not surprising as nerve injuries are usually caused by compression of the peripheral nerves during delivery especially in large babies. Studies ${ }^{[6,23,26,27]}$ have shown that Caesarean section was associated with less birth injuries. Birth weight was observed to be significantly associated with the incidence of birth injuries as documented by Ekwochi et $\mathrm{al}^{[18]}$ in their 4years prospective study in Enugu, south east Nigeria while Mosavat and Zamani ${ }^{[12]}$ showed that birth weight was a strong predictor for birth injuries. In the present study, soft tissue injuries such as lacerations were observed to be commoner in operative deliveries such as Caesarean section than in normal vaginal deliveries. It is pertinent to note that there was no significant association of birth injuries with gestational age as also reported by Osinaike et al. ${ }^{[16]}$ In contrast however, Borna et $\mathrm{al}^{[13]}$ in their 3years prospective cohort study using multiple regression analysis showed gestational age as a significant risk factor for birth injuries. Similarly, Chukwubuike et $\mathrm{al}^{[4]}$ also reported significant association of gestational age with birth injuries. This difference could be as a result of varying study designs.

More than 3/4ths of neonates with birth injuries were discharged home giving a mortality rate of $7.7 \%$. The mortality rate in the present study was lower than the $9.6 \%$ and $8.4 \%$ documented in India $^{[11]}$ and Nigeria $^{[28]}$ but higher than the $5.5 \%, 2.5 \%$ and 2\% reported in Enugu, south east Nigeria $^{[4,18]}$ and $\operatorname{Iran}^{[13]}$ respectively. The varying mortality rates could be because of the different types of birth injuries prevalent in the various geographic locations, their severity, comorbid health conditions and the quality of care provided.

\section{CONCLUSION}

The incidence of birth injuries admitted in the neonatal unit of the Rivers State University Teaching Hospital was 6.9 per 1000 live births with male preponderance. The commonest birth injuries observed were neurological injuries, extracranial injuries and the soft tissue injuries. Neurological injuries were significantly associated with the mode of delivery and birth weights of the neonates while soft tissue injuries were significantly associated with the mode of delivery and sex of the neonates. The mortality rate of neonates with birth injuries was high being $7.7 \%$. Thus, a high index of suspicion of at risk pregnancies with good obstetric practices will thus reduce the incidence while early diagnosis and prompt treatment will reduce morbidity and increase the chances of survival.

\section{ACKNOWLEDGEMENT}

We acknowledge the research team, resident doctors, nurses as well as the nonclinical staff of the special care baby unit.

The research was fully sponsored by the researchers and as such there was no external funding of the research.

\section{Conflict of Interest: None}

\section{Source of Funding: None}

\section{Ethical Approval: Approved}

\section{REFERENCES}

1. Ojumah N, Ramdhan R C, Wilson C, et al. Neurological Neonatal Birth Injuries: a literature review. Cureus 2017; 9(12): e1938. DOI 10.7759/cureus.1938 
2. Akangire G, Carter B. Birth injuries in neonates. Pediatr Rev 2o16:37(11);451-462. DOI: 10.1542/pir.2015-0125.

3. Ekwuochi U, Osuorah DC, Nwabueze AI. Birth injuries in newborns; a prospective study of deliveries in south east Nigeria. Afr J Med Health Sci. 2021:20(4);41-46. DOI: 10.5897/AJMHS2021.0149

4. Chukwubuike KE, Ekwochi U E, Enebe JT, et al. Profile of Birth Injuries in a Tertiary Hospital in Enugu, Nigeria. Am J Biomed Life Sci.2019:7(5);99-103. doi: 10.11648/j.ajbls.20190705.11

5. Pius S, Ibrahim HA, Ibrahim BA, et al. Incidence and characteristics of neonatal birth injuries in Maiduguri North-Eastern Nigeria. Niger J Paediatr 2018; 45 (2):99 105. DOI:http://dx.doi.org/10.4314/njp.v45i2.5

6. Mah EM, Foumane P, Ngwanou DH, et al. Birth Injuries in Neonates at a University Teaching Hospital in Cameroon: Epidemiological, Clinical and Therapeutic Aspects. Open J Pediatr. 2017;7:51-58. https://doi.org/10.4236/ojped.2017.71008

7. Abedzadeh-Kalahroudi M, Talebian A, Jahangiri $\mathbf{M}$, et al. Incidence of Neonatal Birth Injuries and Related Factors in Kashan, Iran. Arch Trauma Res. 2015; 4(1): e22831. DOI: 10.5812/atr.22831

8. Prabhu RS, Sajjid M, Anandan H. Incidence and Predisposing Factors of Birth Trauma in a Tertiary Care Hospital in Chennai, India: A Prospective Study. Int J Sci Stud 2017;4(10):29-33.

DOI: 10.17354/ijss/2017/06.

9. Pressler JL. Classification of major newborn birth injuries. J Perinat Neonat Nurs. 2007;22(1):60-67.

10. Chukwuneke FN. Medical incidents in developing countries: A few case studies from Nigeria. Niger $\mathrm{J}$ Clin Pract 2015;18:S20-S4. DOI: $10.4103 / 1119$ 3077.170821

11. Warke C, Malik S, Chokhandre M, et al. Birth injuries - A review of incidence, perinatal risk factors and outcome. Bombay Hosp J 2012; 54(2): 202-208

12. Mosavat SA, Zamani M. The incidence of borth trauma among liveborn term neonates at a referral hospital in Rafsanjan, Iran. J Maternal-Fetal Neonatal Med 2008; 21(5): 337-339. https://doi.org/10.1080/1476705 0801927921
13. Borna H, Borna S, Mohseni SM, et al. Incidence of and risk factors for birth trauma in Iran. Taiwan J Obstet Gynecol 2010; 49(2): 170-174

14. Kekki M, Salohen A, Tibtonen K, et al. The incidence of birth injuries decreased in Finland between 1997 and 2017: A nationwide register study. Acta Paediatrica 2020; $\quad$ 109: 2562-2569. https://doi.org/10.1111/apa.15267

15. Sauber-Scatzch EK, Markovic N, Bordna LM, et al. Descriptive epidemiology of birth trauma in the United States in 2003. Paediatr Perinatol Epidemiol 2010; 24(2): 116-124

16. Osinaike BO, Akinseye LOO, Akiyode OR, et al. Prevalence and predictive factors of birth traumas in neonates presenting to the children emergency center in south west Nigeria. J Clin Sci 2017; 14(4): 167-172. DOI: $10.4103 /$ jcls_62_16

17. Onuoha KM, Omotola OE, Orimolade EA, et al. Neonatal birth injuries: An Orthopaedic clinic presentation. Am J Biomed Sci \& Res 2020; 7(6): DOI: 10.34297/AJBSR.2020.07.001210

18. Ekwochi U, Osuorah DC, Asinobi IN. Birth injuries in newborns: A prospective study of deliveries in south east Nigeria. Afr J Med Health Sci 2017; 20(4): 41-46. https:// doi.org/10.5897/AJMHS2021.0149

19. Rizwan-u-zama R, Jeergal NA, Thobbi AN, et al. A clinical study of neonatal birth injuries in a tertiary care hospital - Neonatal intensive care unit Bijapur. Indian J Child Health 2020; 7(7): 288-290. DOI: 10.32677/IJCH.2020.v07.i07.002

20. Ray S, Mondal R, Samanta M, et al. Prospective study of neonatal birth trauma. Indian Perspective J Clin Neonatol 2016; 5: 91-95

21. Pinto D, David LS, Kulkarni N, et al. Risk factors associated with major neonatal birth injuries during Caesarean section in a tertiary care hospital in southern India. J Clin Diagn Res 2018; 12: QC14-7

22. Ricart W, Lopez J, Mozas J, et al. Maternal glucose tolerance status influences the risk of macrosomia in male but not in female fetuses. J Epidemiol Community Health 2009; 63: 64-68

23. Linder N, Linder I, Fridman E, et al. Birth trauma risk factors and short term neonatal outcome. J Matern Fetal Neonatal Med 
Boma Awoala West et.al. Incidence, pattern and outcome of birth injuries as seen in a tertiary hospital in Southern Nigeria.

2013; 26(15): 1491-1495. Doi: 10.3109/14767058.2013.789850

24. Yvonne ST, Julie AL, Myia JW. Assessed from https: www.mayoclinic.org/testprocedures/forceps-

delivery/basics/risks/PRC-2014, Assessed on 23/05/2021

25. Njokanma OF, Kehinde O. Mechanical birth trauma - An evaluation of predisposing factors at the Ogun State University Teaching Hospital, Sagamu. Niger J Paediatr 2012; 29(3): 61-65

26. Awari BH, Al-Habdan I, Sadat-Ali M, et al. Birth associated trauma. Saudi Med J 2003; 24(6): 672-674

27. Saeedi R, Maemoori GA, Ayati S, et al. Comparison of neonatal complications in newborns by Caesarean and vaginal delivery. J Sabzevar Univ Med Sci 2009; 16(2): 108-113

28. Oluwadiya K, Olusinde A, Ukpai O, et al. Birth injury: A retrospective study of 146 cases in three Teaching Hospitals in Nigeria. The internet $J$ Pediatr Neonatal 2004; 5(2): $1-5$

How to cite this article: West BA, Okari T. Incidence, pattern and outcome of birth injuries as seen in a tertiary hospital in Southern Nigeria. International Journal of Research and Review. 2021; 8(6): 8-17. DOI: https://doi.org/10. 52403/ijrr.20210602 